\title{
Causes and consequences of song amplitude adjustment in a territorial bird: a case study in nightingales
}

\author{
HENRIK BRUMM \\ Institute of Biology, Department of Behavioural Biology, Free University of Berlin, \\ Haderslebener Str. 9, 12163 Berlin, Germany
}

Manuscript received on January 15, 2004; accepted for publication on February 5, 2004.

\begin{abstract}
Vocal amplitude, one of the crucial factors for the exchange of acoustic signals, has been neglected in studies of animal communication, but recent studies on song variation in Common Nightingales Luscinia megarhynchos have revealed new insights into its importance in the singing behavior of territorial birds. In nightingales song amplitude is not maximized per se, but is individually regulated according to the level of masking background noise. Also, birds adjust their vocal intensity according to social variables, as in male-male interactions. Moreover, during such interactions, males exploited the directionality of their songs to broadcast them in the direction of the intended receivers ensuring the most effective signal transmission. Studies of the development of this typical long-range signaling suggest that sound level is highly interrelated with overall developmental progression and learning, and thus should be viewed as an integral part of song ontogeny. I conclude that song amplitude is a dynamic feature of the avian signal system, which is individually regulated according to the ecological demands of signal transmission and the social context of communication.
\end{abstract}

Key words: acoustic communication, birdsong, Lombard effect, background noise, song development, vocal amplitude.

\section{INTRODUCTION}

The key properties of acoustic signals are frequency, duration, and amplitude. The frequency and temporal characteristics of animal vocalizations have been well studied in a variety of taxa, but much less is known about the role of vocal amplitude (Bradbury and Vehrencamp 1998). This is surprising, since the amplitude of an acoustic signal is a key factor for the exchange of information, determining the broadcast area, or active space, of the signal (Marten and Marler 1977). However, it is important to be clear that the communication range is not only determined by the absolute signal amplitude. The level and spectral characteristics of background noise also contribute

E-mail: brumm@zedat.fu-berlin.de considerably to the transmission distance, because detection and recognition of signals substantially depend on the signal-to-noise ratio (Klump 1996).

In addition, the intensity of animal vocalizations can also encode information that is used by a receiver for decisions relevant to sexual selection. For instance, the sound level of male vocalizations and stridulations affects female mating preferences in several anuran and insect species (review in Gerhardt and Huber 2002), as well as in Red-winged Blackbirds Agelaius phoeniceus (Searcy 1996). In addition to mate choice, another mechanism of sexual selection is male-male competition. Vocal amplitude can also be important to repel rival males, as it has been shown for anurans. In birds, similar 
evidence has been obtained for Eurasian Blackbirds Turdus merula. The strength of territorial male responses increased with increasing song amplitude of simulated rival males, suggesting that the intensity of territorial songs is used by receiving males to regulate distance (Dabelsteen 1981, Todt 1981).

Despite its significance, the use and regulation of vocal amplitude has been neglected. This is partly due to methodological difficulties and, in the sphere of birdsong, to the fallacy that the amplitude of territorial songs is a trait that does not vary much.

To help filling this gap, my co-workers and I examined whether and how a territorial songbird, the Common Nightingale Luscinia megarhynchos (hereafter called nightingale), is able to adjust the intensity of its song. Nightingales have a discontinuous singing style and individual song repertoires can comprise about 200 song types (Hultsch and Todt 1982). There has been extensive research on song development and learning (review in Todt and Hultsch 1996), and the use of songs in male-male interactions (review in Todt and Naguib 2000) in this species.

I have shown that males did not simply maximize the sound pressure levels of their territorial songs. Instead the issue of vocal intensity in territorial songbirds proved to be more complicated than previously supposed. The amplitude of nightingale songs appeared to be individually adjusted according to a variety of factors, especially in relation to the actual environment of the bird and the memory of the songster (Fig. 1). With regards to environmental, or "Umwelt", factors, the level and spectral characteristics of background noise and the social context of singing appear to affect the amplitude of songs. Our results indicate a noise-dependent regulation of vocal amplitude (Brumm and Todt 2002, Brumm 2004) and an increase in song intensity during male-male vocal interactions (Brumm and Todt 2004). Additionally, during vocal development, the intensity of songs was related to memory and learning. Embedded in an age-dependent increase in overall sound level, imitations of acquired model songs were produced with a higher amplitude than the remaining vocal patterns that could not be identified as imitations (Brumm and Hultsch 2001). This plasticity in signal amplitude was based on active variation of vocal sound levels. Directional sound radiation of songs due to sound shadow effects of the birds' head and body also leads to vocal amplitude variations (Brumm 2002). In contrast to active adjustments of song level, this variation in song intensity is merely related to the position of the receiver in relation to the sound source, the singing bird. The directional sound radiation pattern of songs turned out to affect behavior. Territorial males changed their singing direction more often and showed more lateral head movements within songs during solo singing than during vocal interactions with a simulated rival. These results suggest that nightingales either counteract or exploit the directionality of their songs depending on the perceived position of intended receivers (Brumm and Todt 2003).

In the following, I will discuss song amplitude in relation to vocal interactions in birds, ecological and physiological limitations of singing loudly, and the mechanisms of song production.

\section{RAISING THE VOICE WHEN IT MATTERS}

Nightingales produce their territorial songs with relatively low amplitudes during solo performance. As environmental noise levels vary they compensate for interference from background noise by adjusting the amplitude of their vocalizations (Brumm and Todt 2002). This mechanism of vocal amplitude regulation (aka the 'Lombard effect') has also been shown for non-territorial songbirds (Cynx et al. 1998, Kobayasi and Okanoya 2003), non-songbirds (Potash 1972, Manabe et al. 1998, Pytte et al. 2003) and primates (Lombard 1911, Sinnott et al. 1975, Brumm et al. 2004). The Lombard effect enables vocalizing animals to actively maintain the broadcast area, or active space, of their vocalizations by increasing vocal amplitude in response to an increase in the background noise level. In their natural habitats, animals that use sound to communicate have to face a variety of noises, such as abiotic noise, e.g. 


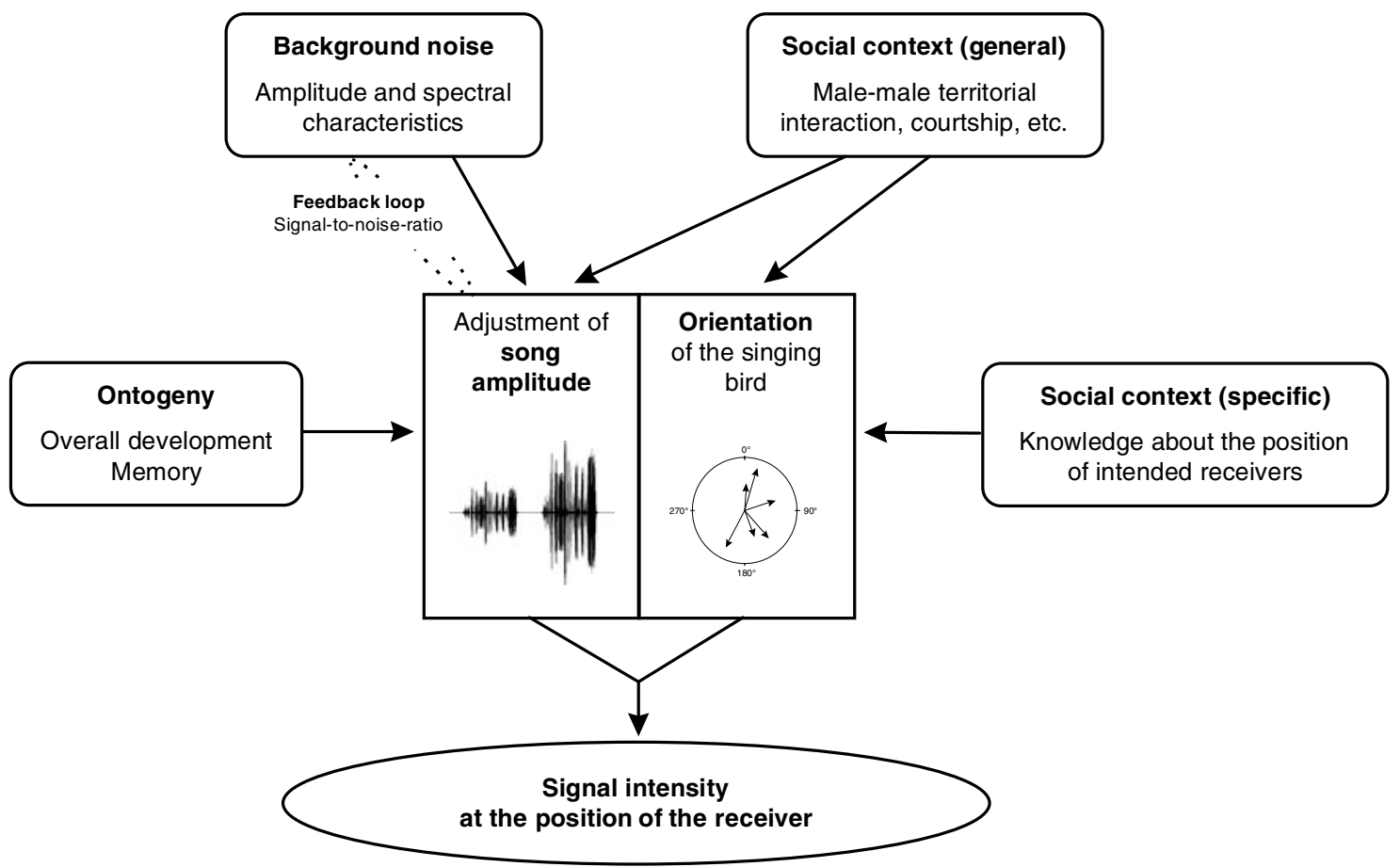

Fig. 1 - Factors affecting the individual adjustment of vocal amplitude and the singer's orientation in male nightingales. In turn, the vocal amplitude and the orientation of the singing bird affect the signal intensity at the position of the receiver, and at the same time they determine the transmission distance of songs.

wind, rain or flowing water, or biotic noise, i.e. interfering sound produced by other animals. Different types of masking sounds affect the regulation of song amplitude, e.g. the sounds from heterospecific birdsong (Brumm and Todt 2004) or man-made sounds, such as traffic noise in urban habitats (Brumm 2004).

Song amplitude can also change with changes in the social context of singing (Brumm and Todt 2004). During vocal interactions with a simulated rival male, nightingales increased the sound level of their songs by more than $5 \mathrm{~dB}$. This augmentation of song level cannot be completely explained by the masking effect of the rival songs, because males increased their vocal intensities to a significantly lesser degree during control experiment with heterospecific songs. By increasing vocal amplitude the birds extend the active space of their songs, helping to broadcast their songs more effectively when interacting with a rival male. In the context of signal transmission, the findings from the ontogenetic analysis of vocal amplitude in nightingales are also of interest. We found that the precursors of sound patterns destined for adult communication were produced with higher amplitudes than those vocalizations that could not be identified as imitations and thus were related to a more or less unspecified singing activity (Brumm and Hultsch 2001).

Additionally, vocal amplitude may also serve as a signal itself, as it has been shown for other song characteristics, such as repertoire size, song rate, timing of singing, and counter-singing patterns (review in Gil and Gahr 2002). More specifically, the sound level a male produces during interactions might well be related to phenotypic or genotypic quality (e.g. body size, age, muscular strength, nutritional state) or motivational states such as the willingness to escalate the interaction. Here, possible addressees may be not only the rival male, but also 
other males or females. These additional receivers can gather information from the dyadic information exchange between the territorial disputants and use this information for individual decisions on future actions, as has been shown for both third party male rivals (e.g. Naguib and Todt 1997, Peake et al. 2001), and females (e.g. Otter et al. 1999, Mennill et al. 2002). In turn, these decisions can affect sexual selection of songs, in terms of female choice or male-male competition. However, the nightingale studies place more emphasis on the significance to the countersinging rival male than to potential third party receivers, since the nightingales use the orientation of their bodies to direct their songs to the male rival (Brumm and Todt 2003).

The finding that nightingales sang with lower vocal amplitude during solo performance and with increased song levels during interactions points to potential costs of singing loudly. This thought seems plausible, because if the production of loud songs was not subject to some costs or constraints, one should expect that birds would always sing with high amplitudes to defend territories and attract distant females.

\section{CONSTRAINTS ON SINGING LOUDLY}

It has been suspected that several factors may limit the production of loud songs in birds, including energy expenditure, social aggression and predation (review in Gil and Gahr 2002). However, whereas the vulnerability of sound-producing insects and anurans to acoustically orientating predators and parasites has been reported in a variety of studies (review in Zuk and Kolluru 1998), evidence of predation cost of singing in birds is still lacking, apart from the study of Mougeot and Bretagnolle (2000) on petrel calls. More research on this issue is needed before the predation costs of birdsong can be assessed.

With regards to social aggression, it seems that the low amplitude of solo singing in nightingales cannot be explained by the avoidance of aggression by other males. Instead I have the impression that quite the reverse is true, for as soon as the presence of a rival was perceived, territorial males increased both amplitude and transmission properties of their songs.

In contrast to anurans (Gerhardt and Huber 2002), the metabolic costs of vocalizing in songbirds are not very high, but increased vocal amplitude causes higher energy expenditure (Oberweger and Goller 2001, Ward et al. 2003). However, a study on singing activity and body weight loss in nightingales suggested rather high energetic costs of singing (Thomas 2002). It remains to be established to what degree energy expenditure limits the performance of loud songs and thus can explain the relatively low sound pressure levels during solo singing.

\section{MECHANISMS OF VOCAL PRODUCTION}

The results of psychoacoustic experiments on nightingales indicate that the Lombard effect is induced most effectively by noise in the spectral region of their songs (Brumm and Todt 2002). The same applies to heterospecific songs which acoustically mask this frequency band (Brumm and Todt 2004). Thus it is reasonable to assume that nightingales assess the signal-to-noise ratio between their songs and the background noise and adjust their vocal intensity accordingly. This finding provides further evidence for a neuronal feedback loop between auditory perception and song production (Leonardo and Konishi 1999). Like humans (Lee 1950, Belmore et al. 1973) adult birds obviously monitor their own vocalizations and the adjustment of vocal amplitude may serve to maintain a specific signal-to-noise ratio that is favorable for signal production.

Perceptual mechanisms are also involved in vocal learning in juvenile birds. Here, birds also monitor their singing and consolidate their vocal memories by auditory feedback (Konishi 1965, Marler 1967). Such feedback mechanism may relate to the production by young nightingales of imitations of acquired model songs with higher amplitude than unidentified patterns (Brumm and Hultsch 
2001). In their attempts to map the acoustic configuration of their own vocalizations on to acquired instructions, songbirds may progressively increase the amplitude of imitations of acquired model songs through a feedback mechanism. Whether auditory feedback can account for both the long-term ontogenetic changes, and also for short-term differences in vocal intensity needs further examination. To sum up, I conclude that song intensity is a significant component in the development of a dynamically unfolding vocal signaling system. Like other major ontogenetic trajectories such as the timing, phonetics and syntax of vocalizations, sound level is probably highly interrelated with overall developmental progression, and thus should be viewed as an integrative part of the vocal learning process.

\section{CONCLUSIONS}

The study of vocal amplitude thus yields new insights not only into the vocal mechanisms of song production but also on the constraints imposed on singing and the role of signal intensity during malemale competition. Further research on the causes and consequences of singing loudly will shed more light on processes of communication in territorial birds. The mechanisms of amplitude variation revealed so far reflect only some aspects of the whole phenomenon. For instance, an increase in vocal amplitude during interactions seems not to be always adaptive. Under certain circumstances, such as specific aggressive contexts or during courtship, birds decrease song intensity (Dabelsteen et al. 1998). Thus the issue of vocal amplitude adjustment in birds is complex and we need more studies examining the social influences on song level variation and the impact of sexual selection, before we can fully understand the role of vocal amplitude in birdsong.

\section{ACKNOWLEDGMENTS}

I thank Dietmar Todt and Henrike Hultsch for their support. In addition, I appreciate the assistance in the field by Tina Sommer and Roger Mundry and the help with the pattern analysis by Nicole Geberzahn and Friederike Kiesselbach. I am also grateful to Peter Marler and Nicole Geberzahn for their comments on the manuscript. Finally, I thank Jacques Vielliard and Maria Luisa da Silva for the kind invitation to the XIX IBAC.

\section{RESUMO}

A amplitude vocal, um dos fatores cruciais para a troca de sinais acústicos, tem sido negligenciada nos estudos da comunicação animal, mas trabalhos recentes sobre a variação do canto do Rouxinol-comum Luscinia megarhynchos evidenciaram sua importância no comportamento de canto das aves territoriais. No rouxinol a amplitude do canto não é aumentada ao máximo per se, mas é regulada individualmente de acordo com o nível de ruído de fundo que mascara o sinal. As aves também ajustam sua intensidade vocal às variáveis sociais, tais como nas interações entre machos. Além disso, durante essas interações, os machos tiram proveito da direcionalidade de seus cantos para emiti-los em direção aos receptores desejados no intuito de garantir a mais eficiente transmissão do sinal. Estudos do desenvolvimento desta sinalização típica de longo alcance sugerem que o nível sonoro seja altamente relacionado com o desenvolvimento geral e a aprendizagem, e deveria portanto ser visto como parte integrante da ontogenia do canto. Concluímos que a amplitude do canto é um parâmetro dinâmico do sistema de sinalização em aves, que é regulado individualmente de acordo com as exigências ecológicas da transmissão do sinal e o contexto social da comunicação.

Palavras-chave: comunicação acústica, canto de aves, efeito Lombard, ruído de fundo, desenvolvimento do canto, amplitude vocal.

\section{REFERENCES}

Belmore NF, Kewley-Port D, Mobley RL and GoodMAN VE. 1973. The development of auditory feedback monitoring: delayed auditory feedback studies on the vocalizations of children aged six month to 18 month. J Speech Hearing Res 16: 709-720.

Bradbury JW and Vehrencamp SL. 1998. Principles of Animal Communication. Sunderland: Sinauer Associates. 
BRumm H. 2002. Sound radiation patterns in nightingale (Luscinia megarhynchos) songs. J Orn 143: 468-471.

BRUmm H. 2004. The impact of environmental noise on song amplitude in a territoral bird. J Anim Ecol: in press.

Brumm H and Hultsch H. 2001. Pattern amplitude is related to pattern imitation during the vocal development of nightingales. Anim Behav 61: 747-754.

Brumm H And TodT D. 2002. Noise-dependent song amplitude regulation in a territorial songbird. Anim Behav 63: 891-897.

Brumm H AND Todt D. 2003. Facing the rival: directional singing behaviour in nightingales. Behaviour 140: 43-53.

Brumm H and Todt D. 2004. Male-male vocal interactions and the adjustment of song amplitude in a territorial bird. Anim Behav 67: 281-286.

Brumm H, Voss K, Köllmer I And Todt D. 2004. Acoustic communication in noise: regulation of call characteristics in a New World monkey. J Exp Biol 207: 443-448.

Cynx J, Lewis R, Tavel B and Tse H. 1998. Amplitude regulation of vocalizations in noise by a songbird, Taeniopygia guttata. Anim Behav 56: 107-113.

Dabelsteen T. 1981. The sound pressure level in the dawn song of the blackbird Turdus merula and a method for adjusting the level in experimental song to the level in natural song. Z Tierpsych 56: 137-149.

Dabelsteen T, McGregor PK, Lampe HM, Langmore NE AND Holland J. 1998. Quiet song in song birds: an overlooked phenomenon. Bioacoustics 9: 89-105.

Gerhardt HC and Huber F. 2002. Acoustic communication in insects and anurans. Chicago: University of Chicago Press.

GiL D And Gahr M. 2002. The honesty of bird song: multiple constraints for multiple traits. Trends Ecol Evol 17: 133-141.

Hultsch H AND TodT D. 1982. Temporal performance roles during vocal interactions in nightingales (Luscinia megarhynchos). Behav Ecol Sociobiol 11: 253260.

KLumP GM. 1996. Bird communication in the noisy world. In: Kroodsma DE AND Miller EH (Eds), Ecology and Evolution of Acoustic Communication in Birds. Ithaca, NY: Cornell University Press, p. 321-338.
Kobayasi KI and OKanoya K. 2003. Sex differences in amplitude regulation of distance calls in Bengalese finches, Lonchura striata var. domestica. Anim Biol 53: 173-182.

Konishi M. 1965. The role of auditory feedback in the control of vocalization in the White-crowned Sparrow. Z Tierpsychol 22: 770-783.

LEE BS. 1950. Effects of delayed speech feedback. J Acoust Soc Am 22: 639-640.

LEONARDO A AND Konishi M. 1999. Decrystallization of adult birdsong by perturbation of auditory feedback. Nature 399: 466-470.

Lombard E. 1911. Le signe de l'élévation de la voix. Annales des Maladies de l'Oreille et du Larynx 37: 101-119.

Manabe K, Sadr EI And Dooling RJ. 1998. Control of vocal intensity in budgerigars (Melopsittacus undulatus): differential reinforcement of vocal intensity and the Lombard effect. J Acoust Soc Am 103: 1190-1198.

Marler P. 1967. Comparative study of song development in sparrows. In: SNOw DW (Ed), Proceedings of the XIV International Ornithological Congress. Oxford: Blackwell, p. 231-244.

Marten K and Marler P. 1977. Sound transmission and its significance for animal communication. Behav Ecol Sociobiol 2: 271-290.

Mennill DJ, Ratcliffe LM and Boag PT. 2002. Female eavesdropping on male song contest in songbirds. Science 296: 873.

Mougeot F and Bretagnolle V. 2000. Predation as a cost of sexual communication in nocturnal seabirds: an experimental approach using acoustic signals. Anim Behav 60: 647-656.

Naguib M And TodT D. 1997. Effects of dyadic vocal interactions on other conspecific receivers in nightingales. Anim Behav 54: 1535-1543.

Oberweger K ANd Goller F. 2001. The metabolic costs of birdsong production. J Exp Biol 204: 3379-3388.

Otter K, McGregor PK, Terry AMr, Burford FrL, Peake TM and Dabelsteen T. 1999. Do female Great Tits (Parus major) assess males by eavesdropping? A field study using interactive song playback. Proc Roy Soc Lond B266: 1305-1309.

Peake TM, McGregor PK, Terry AMR and DabelSTEEN T. 2001. Male Great Tits eavesdrop on simu- 
lated male-to-male vocal interactions. Proc Roy Soc Lond B268: 1183-1187.

Potash LM. 1972. Noice-induced changes in calls of the Japanese quail. Psychonom Sci 26: 252-254.

Pytte CL, Rusch KM and Ficken MS. 2003. Regulation of vocal amplitude by the Blue-throated Hummingbird Lampornis clemenciae. Anim Behav 66: 701-710.

SEARCY WA. 1996. Sound-pressure levels and song preferences in female Red-winged Blackbirds (Agelaius phoeniceus) (Aves, Emberizidae). Ethology 102: 187-196.

Sinnott JM, Stebbins WC and Moody DB. 1975. Regulation of voice amplitude by the monkey. J Acoust Soc Am 58: 412-414.

Thomas RJ. 2002. The costs of singing in nightingales. Anim Behav 63: 959-966.
TODT D. 1981. On functions of vocal matching: effect of counter-replies on song post choice and singing. $\mathrm{Z}$ Tierpsychol 57: 73-93.

Todt D And Hultsch H. 1996. Acquisition and performance of song repertoires: ways of coping with diversity and versatility. In: KRoODSMA DE AND Miller EH (Eds), Ecology and Evolution of Acoustic Communication in Birds. Ithaca, NY: Cornell University Press, p. 79-96.

TodT D AND Naguib M. 2000. Vocal interactions in birds: the use of song as a model in communication. Adv Study Behav 29: 247-296.

Ward S, Speakman JR and Slater PJB. 2003. The energy costs of song in the canary, Serinus canaria. Anim Behav 65: 893-902.

Zuk M AND Kolluru GR. 1998. Exploitation of sexual signals by predators and parasitoids. Quart Rev Biol 73: $415-438$ 